\title{
Cardiac Electrophysiological Study \& Radiofrequency Ablation: Our Experience in Nepal
}

\author{
Sujeeb Rajbhandari, ${ }^{* a}$ Man Bdr KC, ${ }^{a}$ Roshan Raut,${ }^{a}$ Murari Dhungana, ${ }^{a}$ Rajesh Shaha, ${ }^{a}$ Kunal Bikram Shaha ${ }^{a}$ \\ ${ }^{a}$ Shahid Gangalal National Heart Centre, Bansbari, Kathmandu, Nepal.
}

\section{Date of submission \\ November 21st, 2011 \\ Date of acceptance \\ December 19th, 2011 \\ Available online \\ January 25th, 2012}

\section{Keywords \\ cardiac electrophysiological study, radiofre- quency ablation, supraventricular arrhythmia}

\author{
Citation \\ Rajbhandari S, KC Man Bdr, Raut R, et al. \\ Cardiac Electrophysiological Study \& Radi- \\ ofrequency Ablation - Our Experience in Ne- \\ pal. Journal of Advances in Internal Medicine. \\ 2012;01(1)4-7.
}

\begin{abstract}
Background and aim - Cardiac Electrophysiological Study and Radiofrequency ablation is a form of cardiac intervention for diagnosing and treating cardiac arrhythmias. Various catheters are placed in the various parts of the heart to record signals and radiofrequency energy is used for the ablation.
\end{abstract}

Methods - A total of 768 patients with paroxysmal supraventricular arrhythmias underwent the procedure at Shahid Gangalal National Heart Centre, Kathmandu, Nepal in a period between October 2003 to September 2011.

Results - The success rate is high (92\%) and the complication rate is low $(0.8 \%)$ which is comparable to the results shown in various literatures.

Conclusion - Cardiac Electrophysiological study and Radiofrequency ablation is fairly safe and provides a definitive cure to the patients with paroxysmal supraventricular tachycardia.

\section{INTRODUCTION}

Cardiac Electrophysiological Study (EPS) and Radiofrequency Ablation (RFA) is a cardiac interventional method of diagnosis and treatment for cardiac arrhythmias. Before its advent, antiarrhythmic medications were the only treatment option available; which were poor substitutes. The history of EPS goes back to late 70s when it was limited to diagnostic purpose only. ${ }^{1}$ During the initial period, treatment of the arrhythmias started with Direct Current (DC) application. A standard defibrillator was used for that purpose. ${ }^{2}$ Use of DC application had its drawback as it resulted in extremely high temperatures and concussive explosion in the heart. ${ }^{2}$ Later on it was replaced with Radiofrequency Energy. Radio frequency energy is used to create a lesion at the part of the heart where the ectopic focus or the accessory pathway is located. The purpose is to inactivate the accessory pathway, an ectopic focus or simply create a line of conduction block. The usage of radiofrequency energy was first introduced by Huang et al in $1985 .^{3}$

An electrophysiological study consists of placement of catheters in various chambers and structures of heart. They serve the purpose of obtaining intracardiac signals as well as to electrically stimulate various parts of the heart. The aim is to diagnose, measure the basic cardiac intervals, measure the conductivity and refractoriness, to induce arrhythmia, elucidate the mechanism of arrhythmia, to map the site of origin of arrhythmia and to treat various forms of cardiac arrhythmias.

\section{METHODS}

It is a retrospective study. All the patients who underwent cardiac electrophysiological procedure at Shahid Gangalal National Heart Centre in the period between October 2003 to September 2011 were included in the study. The patients were either referred, attended Emergency Room with tachycardia or visited the outpatient department. The EP lab used was Biosense Webster's EP tracer with Stockert EP-Shuttle ablator. In the year 2011 there was one more addition, Saint Judes EP Workmate with $\mathrm{IBI}-1500 \mathrm{~T} 11$ Cardiac ablation generator.

In a standard EP procedure, the patient is draped with all aseptic precautions, venous accesses and if required arterial access are obtained under local anaesthesia. From the right and the left groin two femoral venous accesses from each and from the right neck a right internal jugular access are obtained. In case of a left sided accessory pathway, an additional right femoral arterial puncture is made. All of the vascular accesses were made using modified Seldinger technique. From the internal jugular a 6 French $(\mathrm{Fr})$ decapolar catheter was inserted and placed in coronary sinus, a 6 Fr Josephson type quadripolar catheter was inserted from the right groin access and place over the His bundle region, two quadripolar $6 \mathrm{Fr}$ diagnostic catheters were inserted from the left

\footnotetext{
*Corresponding author

Consultant Cardiologist

Shahid Gangalal National Heart Centre, Bansbari, Kathmandu, Nepal

Email address - sujeebr@hotmail.com
} 
groin and placed in right atrial appendage and right ventricular apex respectively. For ablation purpose blue curve $6 \mathrm{Fr}$ Biosense Webster catheter was used. At occasions red or green curve ablation catheters were used as well.

\section{RESULTS}

A total of 857 patients underwent cardiac electrophysiological procedure during the period at Shahid Gangalal National Heart Centre (SGNHC). Majority of them i.e. 768 underwent EPS plus RFA and only 89 underwent EP study. Among the 89 EP studies, males dominated with $60(67.4 \%)$ compared to 29 (32.6\%) females. Fifty seven had normal EP findings and thirty two had disease of the conduction system. Among the latter the average age was $63 \mathrm{yrs} \pm 17$, the youngest being 28 and the oldest 85 years of age. Eight had EP findings suggestive of sick sinus syndrome and twenty four had evidence of His Purkinje system disease. Thirty two patients with either documented or suspected tachycardia did not have inducible tachycardia.

Among the patients who went EPS and RFA, 347 (45.2\%) were male and $421(54.8 \%)$ were female. The age ranged from 11 years to 78 years, mean being $39.18 \mathrm{yrs} \pm 14$.3. Accessory pathway mediated tachycardia also known as Atrio Ventricular Re entrant Tachycardia (AVRT) formed the major bulk $416(54.2 \%)$ of patients, followed by Atrio Ventricular Nodal Re entrant Tachycardia (AVNRT) 322 (41.9\%), 12 (1.5\%) atrial tachycardia and $18(2.3 \%)$ were others (Atrial flutter, focal PVCs and fascicular VT etc). The mean age of patients with AVRT was $36 \mathrm{yrs} \pm 13.3$ while that of AVNRT was $43.5 \mathrm{yrs} \pm 14.5$. Among the accessory pathways Left sided accessory pathways predominated followed by septal and right sided pathways. Left sided pathways constituted 246 (59.1\%), septal pathway constituted $78(18.8 \%)$, right sided pathway 72 (17.3\%), $16(3.8 \%)$ had more than one accessory pathway and $4(1 \%)$ had Mahaim accessory pathway. Likewise the manifest accessory pathway i.e. documented WPW ECG constituted 223 (56.2\%) and concealed accessory pathway (pathway able to conduct in retrograde direction only) constituted $174(43.8 \%)$. Out of the 768 patients who underwent RFA, ablation was not attempted in $24(9.1 \%)$, failure to ablate in $24(9.1 \%)$, immediate successful ablation was in $699(91 \%)$, tachycardia recurred in $16(2.1 \%)$ and $5(0.7 \%)$ were re ablated at a later date. Regarding complications there were no deaths, two pseudo aneurysms of femoral artery, one high degree atrio ventricular block, one deep venous thrombosis of femoral vein, one peripheral embolization, one severe vasovagal reaction, one cardiac tamponade and one minor bleeding.

\section{DISCUSSION}

$50 \%$ of permanent pacemakers are implanted for bradyarrhythmias caused by Sinus Node Dysfunction (SND). SND showed a median annual incidence of complete AV block of $0.6 \%$ (range $0 \%$ to $4.5 \%$ ) with a total prevalence of $2.1 \%$ (range $0 \%$ to $11.9 \%$ ). ${ }^{4}$ This suggests that the degenerative process also affect the rest of the conduction system, although the rate of progression is slow. ${ }^{4}$

Among the Paroxysmal Supraventricular Tachycardias (PSVTs) the most common is Atrio Ventricular Nodal Re entrant Tachycardia (AVNRT) $52 \% .^{5-9}$ During mid 70 s after almost a decade of experience with Wolf Parkinson White (WPW) syndrome the existence of concealed accessory pathway was discovered. ${ }^{6}$ The presence of concealed accessory pathway accounts for approximately $38 \%$ of patients ${ }^{6}$ with apparent PSVT and about $10 \%$ is due to atrial tachycardia. ${ }^{14-15}$ Atrial tachycardias are usually focal (originates from a single site) in origin and can originate from one or both atria. The sex difference went along with the findings in the literature for both AVNRT and AVRT. Males were $101(31.4 \%)$ while females were $221(68.6 \%)$ in AVNRT and in case of AVRT males were 228 (54.8\%) and the females were

$188(45.2 \%) .^{5-9}$ Contrary to the findings in the literature AVRT predominated in our study followed by AVNRT, one of the reasons being inclusion of patients with overt WPW in our study. Various other studies show the incidence of concealed by pass tract to range from $15 \%$ to $50 \%{ }^{5-13}$ If we solely consider the patients with only concealed accessory pathway in our study, the number drops to 174 (22.6\%).

The prevalence of ventricular pre excitation is thought to be 0.1 to 3 per 1000 people in the general population. ${ }^{53,54}$ Estimates of arrhythmia incidence in patients with pre excitation vary widely, ranging from $12 \%$ to $80 \%$ in several surveys. Approximately 4 newly diagnosed cases of WPW syndrome per 100,000 population occur each year. The location of the APs, in decreasing order of frequency, is $53 \%$, the left free wall, $36 \%$, posteroseptal, $8 \%$, right free wall, and $3 \%$, anteroseptal.

Approximately $80 \%$ of patients with WPW syndrome have a reciprocating tachycardia, $15-30 \%$ will develop AF, and $5 \%$ have atrial flutter. ${ }^{56,57}$

WPW syndrome is found in persons of all ages. Most patients with WPW syndrome present during infancy. However, a second peak of presentation is noted in school-aged children and in adolescents. This interesting bimodal age distribution is due to permanent or transitory loss of pre excitation during infancy in some patients and during late adolescence in others. The prevalence of WPW syndrome decreases with age as a consequence of apparent attenuation of conduction speed in the AP. About one fourth of patients lose pre excitation over a 10-year period, probably as a result of fibrotic changes at the site of insertion of the accessory bypass tract. Cases have been described in which ECG evidence of pre excitation disappears completely. One tenth of patients with concealed APs lose retrograde conduction over 10 years.

In asymptomatic patients, antegrade conduction across the accessory pathway (AP) may spontaneously disappear with advancing age (one fourth of patients lose antegrade bypass tract conduction over 10 years). In patients with abnormal ECG findings indicative of WPW syndrome, the frequency of SVT paroxysms increases from $10 \%$ in people aged $20-39$ years to $36 \%$ in people older than 60 years. ${ }^{16}$ Overall, about $50 \%$ of patients with WPW develop tachyarrhythmias. WPW syndrome has been found to be more frequent in males. One study documented a male-to-female ratio of approximately $2: 1$. Another reported 1.4 cases of WPW syndrome per 1000 men and 0.9 cases per 1000 women. A third study found a 3.5 -fold higher prevalence of WPW syndrome in men. No clear racial predilection appears to exist. The success rates for AVNRT ablation from reported trials are more than $95 \% .^{17-19}$ We had only one relapse giving us the success rate of $99.7 \%$ with a solitary complication, as one patient developed high degree AV block which is comparable to one series by Huang et al in which 6 patients out of 2333 developed complete heart block. ${ }^{20}$ Success rates for left sided pathway is highest of any AP location and are typically greater than $90 \% .^{21-31}$ In our series we successfully ablated 237 out of 246 left sided pathways giving the success rate of $96.3 \%$. We mostly used the retrograde aortic approach for the ablation of the left sided pathways, but at occasions especially for the pathways located anteriorly trans septal approach was used. 
Supero paraseptal APs comprise $6 \%-7 \%$ of all APs in most large series. About $80 \%$ of them exhibit anterograde conduction while $20 \%$ are retrograde only conducting (concealed); $5 \%$ conduct exclusively in the anterograde direction. ${ }^{51}$ Mid septal pathways are $5 \%$ or less of all accessory pathways. ${ }^{51}$ Due to close proximity of AV node and Bundle of His there is increased risk of damage to these structures during ablation, but we did not have any incidence of such damage in our study. Studies indicate the success rate for superoparaseptal pathways to be $95 \%$ with $1 \%$ risk of heart block and $10 \%$ risk of right bundle branch block. ${ }^{52}$ We had one incidence of right bundle branch block after ablation of superoparaseptal pathway. For practical purpose it should be noted that antero septal and parahisian pathways are both considered to be superoparaseptal pathway. For postero septal pathways the success rate is similarly high, at $93 \%-98 \%,{ }^{36-43}$ our success rate for septal pathway is $80.8 \%$ which is mainly due to pathways which had antero septal, mid septal or para Hisian locations and were not attempted due to close proximity to AV node and His bundle. The success rates for the right free wall are the lowest for any AP

\section{REFERENCES}

1. Damato AN, Lau SH, Helfant R, et al. Study of heart block in man using His bundle recordings. Circulation. 1969;3:297-305. 2. Fontaine G, Volmer W, Nienaltowska E, et al. Approach to the physics of fulguration. In: Fontaine G, Scheinman M, eds. Ablations in cardiac arrhythmias. Mount Kisco, NY: Futura Publishing. 1987. 3. David E. Haines. Catheter Ablation of Cardiac Arrhythmias. Biophysics of Radiofrequency Lesion Formation. In: Shoei K. Stephen Huang, Mark A. Wood, editor. Catheter Ablation of Cardiac Arrhythmias, First Ed, Philadelphia - Elsevier, 2006:3-30.

4. Rosenqvist M, Obel IW. Atrial pacing and the risk for AV block: is there a time for change in attitude? Pacing Clin Electrophysiol. 1989;12:97-101.

5. Wu D, Denes P. Mechanisms of paroxysmal supraventricular tachycardia. Arch of Intern Med. 1975;135:437.

6. Josephson ME. Supraventricular Tachycardias. In: Clinical Cardiac Electrophysiology: Techniques and Interpretations, 3rd Edition, Lippincott Williams \& Wilkins 2002;219.

7. Josephson ME, Kastor JA. Supraventricular tachycardia: mechanisms and management. Ann of Intern Med. 1977;87:346.

8. Josephson ME. Paroxysmal supraventricular tachycardia: an electrophysiological approach. Ann J Cardiol. 1978;41:1123.

9. Akhtar M. Supraventricular tachycardias. Electrophysiologic mechanisms, diagnosis and pharmacologic therapy. In: Josephson ME, Wellens HJJ, eds. Tachycardias: mechanisms, diagnosis, treatment. Philadelphia: Lea \& Febiger, 1984:137.

10. Spurrrel RAJ, Krikler DM, Swoton E. Concealed bypasses of the atrio- ventricular node in patients with paroxysmal supraventricular tachycardia revealed by intracardiac electrical stimulation and verapamil. Am J Cardiol. 1974; 33:590.

11. Farshidi A, Josephson ME, Horowitz LN. Electrophysiologic characteristics of concealed bypass tracts: clinical and electrocardiographic correlates. Am J Cardiol. 1978:41:1052.

12. Ross DL, Uther JB, Diagnosis of concealed accessory pathways in supraventricular tachycardia. PACE. 1984;7:1069.

13. Josephson ME, Wellens HJJ. Electrophysiologic evaluation of supraventricular tachycardia. In: Scheinman MM, ed. Cardiology location, ranging from $66 \%-100 \%$ in different series averaging about $90 \%{ }^{44-50}$ If we consider postero septal pathways only then our success rate goes up to 46 out of 51 i.e. $90.2 \%$.

Complications are related to vascular access, vessel involved, location of the region of AP, slow pathway or ectopic foci in the heart, catheter manipulation, trans septal or trans aortic approach and radiofrequency energy delivery. We had very low rate of complications of $0.8 \%$ which is well below that shown in the literature.

\section{CONCLUSION}

In conclusion radiofrequency ablation is a safe and a definitive cure for significant majority of patients with Paroxysmal Supraventricular Tachycardias (PSVTs). This form of interventional treatment has high rate of immediate and long term success with low rate of complications. Shahid Gangalal National Heart Centre situated at Bansbari is the only centre providing such facility inside Nepal. With success rates comparable to the literature and remarkably low rate of complications it is definitely the treatment of choice for PSVTs.

clinics: Advances in supraventricular tachycardia. Philadelphia: WB Saunders. 1997:34:567-86.

14. Gillette PC, Garson A Jr. Electrophysiologic and pharmacologic characteristics of automatic ectopic atrial tachycardia. Circ 1977; 57:556-71.

15. Mehta AV, Sanchez GR, Sacks EJ et al. Ectopic automatic atrial tachycardia in children: clinical characteristics, management and follow - up. J Am Coll Cardiol. 1988;11:379.

16. Brembilla-Perrot B, Yangni N'da O, Huttin O, Chometon F, Groben L, Christophe C. Wolff-Parkinson-White syndrome in the elderly: clinical and electrophysiological findings. Arch Cardiovasc Dis. 2008;101:18-22.

17. Taylor GW, Kay NG: Selective slow pathway ablation for treatment of AV nodal re-entrant tachycardia. In Huang SK, Wilber Dj (eds): Radiofrequency Catheter Ablation of Cardiac Arrhythmias. Armonk, N.Y.:Futura, 2000.p.423-61.

18. Geita F, Riccardi R, Calo L: Importance and implications of the occurrence of AV block following radiofrequency ablation. Heart 1999;89:516-9.

19. Thakur RK, Flein Gj, Yee R: Junctional tachycardia: A useful marker during radiofrequency ablation for the treatment of atrioventricular nodal re entrant tachycardia: A report of two cases. Heart. 1998;79:616-8.

20. Hugh Thomas McElderry, G. Neal Kay. Ablation of Atrioventricular Nodal Reentry by the Anatomic Approach. In: Huang SK, Mark A W. Catheter Ablation of Cardiac Arrhythmias; Saunders Elsevier, 2006:342

21. Swartz F, Tracy CM, Fletcher RD: Radiofrequency endocardial catheter ablation of accessory atrioventricular pathway atrial insertion sites. Circulation. 1993;87:487-99.

22. Fisher WB, Swartz JF: Three dimensional electrogram mapping improves ablation of left sided accessory pathways. Pacing Clin Electrophysiol. 1992;15:2344-56.

23. De Ponti R, Zardini M, Stroti C, et al. Trans - septal catheterization for radiofrequency catheter ablation of cardiac arrhythmias. Eur Heart J. 1998;19:943-50.

24. Yip ASB, Chow WH, Yung TC, et al. Radiofrequency catheter ablation of left sided accessory pathways using a transseptal 
technique and specialized long intravascular sheaths. Jpn Heart J 1997;38:643-50.

25. Manolis AS, Wang PJ, Estes NAM. Radiofrequency ablation of atrial insertion of left - sided accessory pathways guided by the “W sign”. J Cardiovasc Electrophysiol. 1995;6:1068-76.

26. Lesh MD, Van Hare GF, Schamp DJ, et al. Curative percutaneous catheter ablation using radiofrequency energy for accessory pathways in all locations. Results in 100 consecutive patients. J Am Coll Cardiol. 1992;19:1303-9.

27. Chen X, Borggrefe M, Hindricks G, et al. Radiofrequency ablation of accessory pathways. Characteristics of transiently and permanently effective pulses. Pacing Clin Electrophysiol. 1992;15:1122-30.

28. Lanberg JJ, Calkins H, Kim Y - N, et al. Recurrence of conduction in accessory atrioventricular connections after initially successful radiofrequency catheter ablation. J Am Coll Cardiol. 1992;19:1588-92.

29. Deshpande SS, Bremmer S, Sra JS, et al. Ablation of left free wall accessory pathways using radiofrequency energy at the atrial insertion site: Transseptal versus transarortic approach. J Cardiovasc Electrophysiol. 1994;5:219-31.

30. Lesh MD, Van Hare GF, Scheinman MM, et al. Comparison of the retrograde and transseptal methods for ablation of left free - wall accessory pathways. J Am Coll Cardiol. 1993;22:542-9.

31. Natale A, Wathen M, Yee R, et al. Atrial and ventricular approaches for radiofrequency catheter ablation of left sided accessory pathways. Am J Cardiol. 1992;70:114 -6.

32. Saul JP, Hulse JE, De W, et al. Catheter ablation of accessory atrioventricular pathways in young patients. Use of long vascular sheaths, the transseptal approach and a retrograde left posterior parallel approach. J Am Coll Cardiol. 1993;21:571-83.

33. Manolis AS, Wang PJ, Estes NAM. Radiofrequency ablation of left - sided accessory pathways: Transaortic versus transseptal approach. Am Heart J. 1994;125:896-902.

34. Vora AM, McMahon S, Jazayeri MR, Dhala A. Ablation of atrial insertion sites of left sided accessory pathways in children: Efficacy and safety of transseptal versus transaortic approach. Pediatr Cardiol. 1997;18:332-8.

35. Ma C, Dong J, Yang X, et al. A randomized comparison between retrograde and transseptal approach for radiofrequency ablation of left sided accessory pathways. Pacing Clin Electrophysiol. 1995 ;8:479.

36. Calkins H, Kim Y - N, Schmaltz S, et al. Electrogram criteria for identification of appropriate target sites for radiofrequency catheter ablation of accessory atrioventricular connections. Circulation. 1992;85:658-73.

37. Calkins H, Yong P, Miller J, et al. Catheter ablation of accessory pathways, atrioventricular nodal re entry tachycardia, and the atrioventricular junction: Final results of a prospective, multicenter clinical trial. Circulation. 1999;99:262-70.

38. Jackman WM, Wang X, Friday KJ, et al. Catheter ablation of accessory atrioventricular pathways (Wolf - Parkinson - White syndrome) by radiofrequency current. N Engl J Med. 1991;324:160511.

39. Chiang C, Chen S, tai C, et al. Prediction of successful ablation site of concealed posteroseptal accessory pathway by a novel algorithm using baseline electrophysiological parameters. Circulation. 93:982-91, 1996.

40. Dhala AA, Deshpande SS, Brenner S, et al. Transcatheter ablation of posteroseptal accessory pathways using a venous approach and radiofrequency energy. Circulation. 1994;90:1799-810.

41. Haissaguerre M, Gaita F, Marcus FJ, Clementy J: Radiofrequency catheter ablation of accessory pathways: A contemporary review. $J$ Cardiovasc Electrophysiol. 1994;5:533-52.

42. Haissaguerre M, Monteserrat P, Warin JF, et al: Catheter ablation of left postero septal accessory pathways and of long RP tachycardias with a right endocardial approach. Eur Heart J. 1991;12:845-59.

43. Gaita F, Haissaguerre M, Giustetto C, et al. Catheter ablation of permanent Junctional reciprocating tachycardia with radio frequency current. J Am Coll Cardiol. 1995;25:648-54.

44. Swartz F, Tracy CM, Fletcher RD. Radiofrequency endocardial catheter ablation of accessory atrioventricular pathway atrial insertion sites. Circulation. 1993;87:487-99.

45. Haissaguerre M, Gaita F, Marcus FL, et al. Radiofrequency catheter ablation of accessory pathways: A contemporary review. $J$ Cardiovasc Electrophysiol. 1994;5:532-52.

46. Nakao K, Seto S, Iliev II, et al: Simultaneous atrial and ventricular pacing to facilitate mapping of concealed left sided accessory pathways. Pacing Clin Electrophysiol. 1992;25:922-8.

47. Drago F, Silvetti M, Di Pino A, et al. Exclusion of fluoroscopy during ablation treatment of right accessory pathway in children. J Cardiovasc Electrophysiol. 2002;13:778 -82.

48. Lesh MD, Van Hare GF, Schamp DJ, et al. Curative percutaneous catheter ablation using radiofrequency energy for accessory pathways in all locations. Result in 100 consecutive patients. J Am Coll Cardiology. 1992;19:1303-9.

49. Calkins H, Young P, Miller J, et al. Catheter ablation of accessory pathways, atrioventricular nodal re-entrant tachycardia, and the atrioventricular junction. Final results of a prospective, multicenter clinical trial. Circulation. 1999;99:262-70.

50. Jackman WM, Wang X, Friday KJ, et al. Catheter ablation of accessory atrioventricular pathways (Wolf - Parkinson - White syndrome) by radiofrequency current. N Engl J Med. 1991 ;324:1605-11.

51. Josephson ME. Clinical Cardiac Electrophysiology: Techniques and Interpretations, 3rd Edition, Lippincott Williams \& Wilkins 2002.p.414.

52. Kuck KH, Ouyang F, Goya M, Boczor S. Ablation of antero septal and mid septal accessory pathways. In Zipes DP, Haissaguerre M (EDS): Catheter ablation of parahisian accessory pathways. J Cardiovasc Electrophysiol. 1997;8:1357-65.

53. Chung K - Y, Walsh TJ, Massie E. Wolf - Parkinson - White syndrome. Am Heart J. 1965;69:1.

54. Mandel WJ, Laks MM, Fink B, Obayashi K. Comparative electrophysiologic features of WPW syndrome in the pediatric and adult patient. Am J Cardiol. 1974;33:155.

55. Garson A HJr, Gillette PC, McNamara DG. Supraventricular tachycardia in children: clinical features response to treatment and long term follow - up in 217 patients. J Pediatrics. 1981:98:875. 56. DellaBella P, Brugada P, Talajic M, et al. Atrial fibrillation in patients with an accessory pathway: Importance of the conductive properties of the accessory pathway. J Am Coll Cardiol. 1991;17:1352-6.

57. Haissaguerre M, Fishcher B, Labbe T, et al. Frequency of recurrent atrial fibrillation after catheter ablation of overt accessory pathways. Am J Cardiol. 1992;69:493-7. 